\title{
Pro-tobacco marketing and anti-tobacco campaigns aimed at vulnerable populations: A review of the literature
}

\author{
Tess Boley Cruz', Shyanika W. Rose ${ }^{2,3}$, Brianna A. Lienemann ${ }^{1,4}$, M. Justin Byron ${ }^{5}$, Helen I. Meissner ${ }^{6}$, Lourdes \\ Baezconde-Garbanati' ${ }^{1}$ Li-Ling Huang ${ }^{7}$, Dana M. Carroll' ${ }^{8}$, Claradina Soto ${ }^{1}$, Jennifer B. Unger ${ }^{7}$
}

\begin{abstract}
INTRODUCTION We reviewed research literature on pro-tobacco marketing and anti-tobacco campaigns targeting eight vulnerable populations to determine key findings and research gaps. Results can inform tobacco policy and control efforts and the design of public education campaigns for these groups.

METHODS Five journal databases in medicine, communication, and science, were used to identify 8875 peer-reviewed, original articles in English, published in the period 2004-2018. There were 144 articles that met inclusion criteria on pro-tobacco marketing or anti-tobacco campaigns aimed at eight US groups: women of reproductive age, racial/ethnic minority groups (African American, Hispanic/Latino, Asian/Pacific Islander and American Indian/Alaska Native), Lesbian/Gay/Bisexual/ Transgender (LGBT) populations, groups with low socioeconomic status, rural/inner city residents, military/veterans, and people with mental health or medical co-morbidities. We summarized the number of articles for each population, type of tobacco, and pro-tobacco or anti-tobacco focus. Narrative summaries were organized by population and by pro-tobacco or anti-tobacco focus, with key strategies and gaps by group.

RESULTS There were more studies on pro-tobacco marketing rather than anti-tobacco campaigns, and on cigarettes rather than other tobacco products. Major gaps included studies on Asian Americans, American Indian/Alaska Natives, pregnant women, LGBT populations, and those with mental health or medical co-morbidities. Gaps related to tobacco products were found for hookah, snus, and pipe/roll-your-own tobacco in the pro-tobacco studies, and for all products except cigarettes in antitobacco studies. Common tobacco industry methods used were tailoring of product and package design and messages that were used to reach and appeal to different sociodemographic groups. Studies varied by research design making it difficult to compare results.

CONCLUSIONS We found major research gaps for specific groups and tobacco products. Public education campaigns need a stronger foundation in empirical studies focused on these populations. Research and practice would benefit from studies that permit comparisons across studies.
\end{abstract}

\author{
AFFILIATION \\ 1 Keck School of Medicine, University \\ of Southern California, Los Angeles, \\ United States \\ 2 Truth Initiative Schroeder Institute, \\ Washington, United States \\ 3 Center for Health Equity \\ Transformation and Behavioral \\ Science, University of \\ Kentucky College of Medicine, \\ Lexington, United States \\ 4 Moores Cancer Center, University \\ of California San Diego, San Diego, \\ United States \\ 5 Department of Family Medicine, \\ School of Medicine, University of \\ North Carolina at Chapel Hill, Chapel \\ Hill, United States \\ 6 Office of Disease Prevention, \\ National Institutes of Health, \\ Bethesda, United States \\ 7 Global Health and Health Security, \\ Taipei Medical University, Taipei, \\ Taiwan \\ 8 Masonic Cancer Center, University \\ of Minnesota, Minneapolis, United \\ States
}

\section{CORRESPONDENCE TO}

Tess Boley Cruz. Institute for Prevention Research, Keck School of Medicine, University of Southern California, 2001 N. Soto Street, Mail Code 9239, Office 312C, Los Angeles, CA 90089, United States. E-mail: tesscruz@usc.edu ORCID ID: https://orcid.org/00000002-5894-1802

\section{KEYWORDS}

pro-tobacco, anti-tobacco, marketing, campaigns, vulnerable populations

Received: 1 January 2019

Revised: 29 July 2019

Accepted: 29 July 2019

\section{INTRODUCTION}

Pro-tobacco marketing and anti-tobacco mass media campaigns can influence the likelihood of initiating and using tobacco ${ }^{1}$. While smoking has declined 
over the past five decades in the United States, disparities persist due to targeting by the tobacco industry and limited reach by tobacco control efforts in certain populations ${ }^{2}$. Analysis of both pro-tobacco marketing and anti-tobacco campaign strategies and gaps can be used to improve the reach and cultural appropriateness of public education campaigns to reduce tobacco use $\mathrm{u}^{3,4}$.

The current study identified and analyzed research on pro-tobacco marketing and anti-tobacco mass media campaigns targeted at eight vulnerable populations in the US. These groups were considered vulnerable because of high rates of tobacco use or complications related to use. Vulnerable populations included: women of reproductive age; racial/ethnic minority groups such as African American (AA), Hispanic/Latino (HL), Asian/Pacific Islander (API), and American Indian/Alaska Native (AI/AN); Lesbian/Gay/Bisexual/and/or Transgender (LGBT) populations; people of low socioeconomic status (SES); populations in rural or inner city geographical location; military/veterans; and people with mental health or with medical comorbidities. These groups experience disparities in tobacco use, tobacco-related diseases, and/or difficulty quitting ${ }^{2,5-7}$. This article reviewed research on the extent, strategies and effects of pro-tobacco marketing or anti-tobacco campaigns that targeted these populations. It adds to existing literature by identifying areas of concentration and gaps in these campaigns. The results can inform prevention and cessation campaigns and tobacco control policies for at-risk populations to reduce tobacco-related disparities.

\section{METHODS}

We conducted a review of the scientific literature to determine patterns in pro-tobacco marketing and antitobacco mass media campaigns targeting vulnerable populations. Citation databases included PubMed, Web of Science, ABI/Inform, Communication Source, and PsycINFO, using search terms that combined tobacco products AND marketing in the title, abstract or keywords, as shown in Table 1. Search terms encompassed all types of tobacco current at the time (e.g. chew tobacco is captured under the header 'tobacco'). Results were limited to peer-reviewed articles in English, from 1 January 2004 through March 2018, encompassing five years before and eight years after the US enacted federal regulation of tobacco (the Family Smoking Prevention and Tobacco Control Act of 2009), yielding 8877 articles. Articles were included if they addressed one of eight vulnerable populations and pro-tobacco marketing or anti-tobacco campaigns, and were primary research studies or analysis of tobacco industry documents focused on the US. These eight groups included racial/ethnic minority groups, women who could become pregnant or have difficulty quitting while pregnant, low-income populations, sexual minorities, rural or inner city urban populations, military or veterans, or populations with either medical or mental health co-morbidities ${ }^{2,5-7}$. This review excluded youth and young adults as a vulnerable population separate from the other vulnerable groups, because previous reviews have focused on marketing to these populations and because the large number of studies $(\mathrm{n}=260)$ required a separate analysis to permit a full

\section{Table 1. Search terms*}

\begin{tabular}{|c|c|c|c|c|}
\hline Tobaceo product identifier(s) & & Varketing, advertising or social marketing identifier(s) & & $\begin{array}{l}\text { United } \\
\text { States } \\
\text { identifier(s) }\end{array}$ \\
\hline $\begin{array}{l}\text { Cigarette; smoking; e-cigarette; e-cig; } \\
\text { electronic cigarette; tobacco; electronic } \\
\text { nicotine delivery system; smoking; smoke; } \\
\text { smoker; vape; vaping; vaper; smokeless } \\
\text { tobacco; snus; cigar; cigarillo; kreteks; bidi; } \\
\text { filtered little cigar; little cigar; waterpipe; } \\
\text { hookah; water pipe; narghile; arghila; } \\
\text { dissolvable tobacco; pipe smoking; tobacco } \\
\text { industry }\end{array}$ & $\sum$ & $\begin{array}{l}\text { Social marketing; business communications; advertising; public } \\
\text { service advertising; advertisements; advertising campaigns; } \\
\text { mass communications communication research; propaganda; } \\
\text { mass media; television advertising; TV advertising; radio } \\
\text { advertising; magazine advertising; point-of-sale advertising; } \\
\text { internet advertising; billboard advertising; social marketing; } \\
\text { promotion; communication; media campaign; mass media; } \\
\text { public education health education; anti-smoking; anti- } \\
\text { tobacco; counter-marketing; counter-advertising; PSA; truth } \\
\text { campaign; tips from a former smoker; the real cost. }\end{array}$ & $\gtreqless$ & $\begin{array}{l}\text { United States; } \\
\text { USA; America }\end{array}$ \\
\hline
\end{tabular}

*Search terms were selected to find both general and specific types of tobacco and marketing/campaigns. Major subject headings for the databases, such as 'tobacco', indexed many types of topics in addition to the specific terms listed. 
Figure 1. PRISMA diagram showing the flow of studies through the screening process

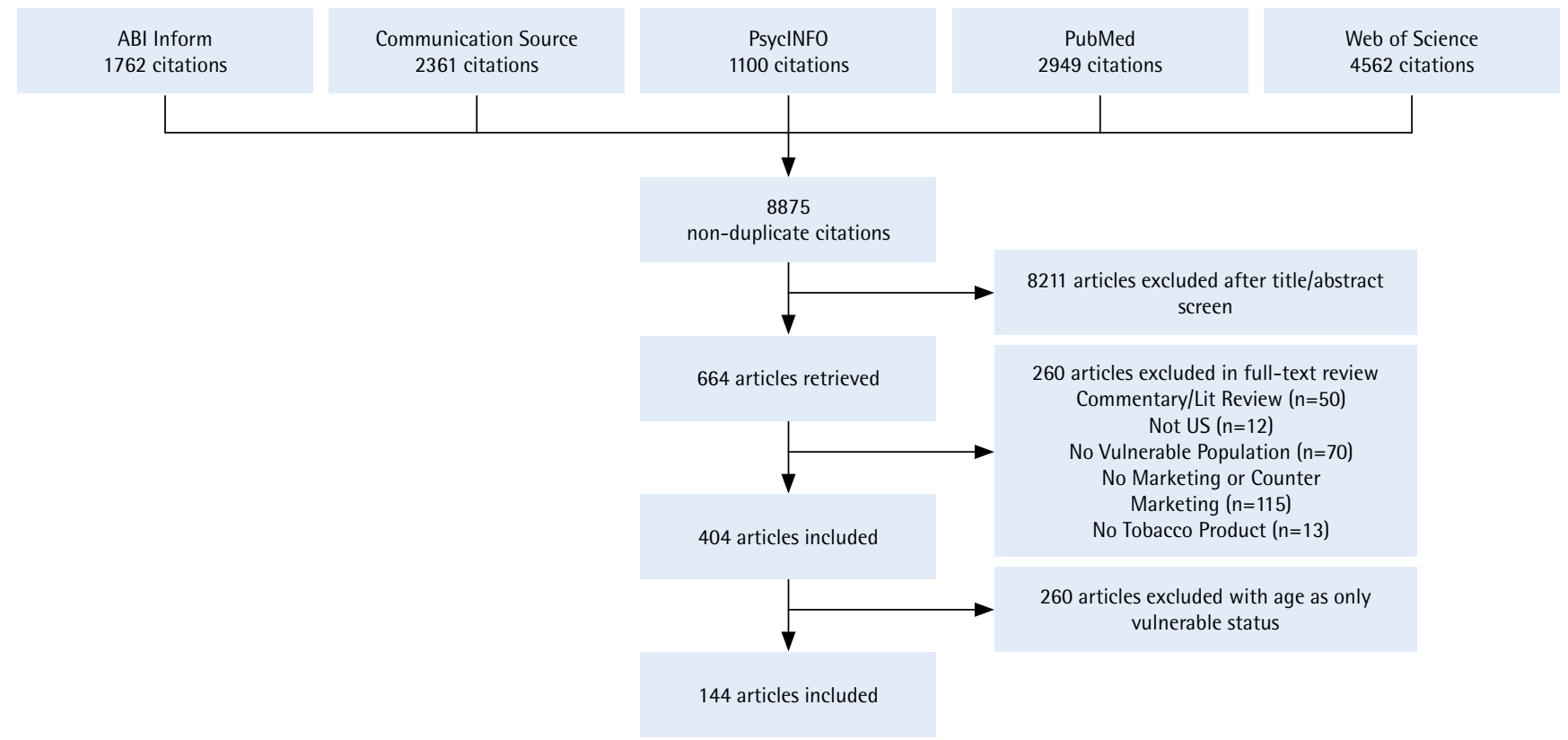

discussion of the work ${ }^{1,2,8}$.

Two coders independently reviewed each article title and abstract, retained the articles that met the inclusion criteria, and coded their focus on protobacco or anti-tobacco, vulnerable population, and type of tobacco product. Discrepant codes were reconciled by discussion, and if still unresolved, then by reading the full article. This process resulted in 146 articles included in the review (Figure 1).

\section{Pro-tobacco marketing or anti-tobacco campaigns}

Tobacco marketing is a broad term that includes paid advertising, promotions, sponsorship, loyalty programs, product design, pricing, and more, run by tobacco manufacturers and distributors. We identified studies as pro-tobacco marketing if they analyzed planned efforts to increase tobacco use, such as greater density of tobacco billboards or promotions in retail outlets in predominantly African American communities. We also included analysis of tobacco industry documents regarding marketing plans aimed at specific groups. Anti-tobacco campaigns included public education campaigns to reduce tobacco use such as a media campaign to encourage pregnant women to stop smoking. Articles about planned media campaigns through media channels (e.g. billboards, Internet), planned media environments (e.g. stores), or movies with smoking were included, if pro-tobacco marketing or anti-tobacco campaigning was their primary focus (e.g. a main unit of analysis, predictor or outcome, not a covariate or one component of a multi-component intervention) and if they also focused on one of our eight vulnerable populations.

\section{Vulnerable populations}

Articles were excluded if they did not focus on at least one of eight vulnerable population groups: 1) racial/ ethnic minorities (AA, HL, API, AI/AN); 2) low SES; 3 ) pregnant women or women of reproductive age; 4) populations in inner city urban or rural areas; 5) military or veterans; 6) sexual minorities (LGBT); 7) people with mental health disorders; and/or 8) people with medical comorbidities. Studies were included if the population was an intended part of the sample in sufficient numbers to draw conclusions about that population, or the only population in the study; and excluded if the vulnerable population variable was a covariate of another analysis or the focus was on a non-vulnerable group (e.g. men as a general group).

\section{Tobacco products}

Included articles referenced one or more tobacco products: cigarettes, cigars/little cigars/cigarillos; smokeless tobacco (ST) including chew, spit or snus; hookah/waterpipe, electronic cigarettes/vaping, pipe 
or roll-your-own tobacco; a specific brand or type of product (e.g. menthol cigarettes); or 'tobacco' as a non-defined general category.

Due to the wide variation in measurement and broad scope of the review, results were summarized narratively regarding marketing practices and outcomes.

\section{RESULTS}

Of the 144 included articles, 64\% $(n=93)$ were considered pro-tobacco, which means they focused on tobacco advertising, promotional efforts and/or placement in films and television. There were fewer studies $(38 \%, n=55)$ on anti-tobacco efforts, which means they analyzed planned prevention and cessation campaigns. Two of the articles were considered both pro-tobacco and anti-tobacco because they analyzed both perspectives (so percentages exceed 100\%). Most $(77 \%, n=111)$ focused on cigarettes, $17 \%(n=25)$ on 'tobacco' as a general product category, $5 \%(n=8)$ on e-cigarettes and $5 \%(n=8)$ on cigars, as shown in Table 2. One article focused on hookah/waterpipe,

Table 2. Articles by tobacco focus and type of product

\begin{tabular}{|c|c|c|}
\hline Product & $\begin{array}{l}\text { Pro tobaceo } \\
\text { marketing }\end{array}$ & $\begin{array}{l}\text { Anti tobaceo } \\
\text { campaigns }\end{array}$ \\
\hline Cigarettes & $57^{a}$ & $55^{b}$ \\
\hline Cigars & $8^{c}$ & 0 \\
\hline Smokeless & $7^{d}$ & 0 \\
\hline Pipe/RYO & 0 & 0 \\
\hline E-cigarettes & $8^{e}$ & 0 \\
\hline Snus & $1^{\mathrm{f}}$ & 0 \\
\hline Hookah & $1^{9}$ & 0 \\
\hline Other & $3^{h}$ & $2^{i}$ \\
\hline General tobacco & $22^{j}$ & $3^{k}$ \\
\hline Total & 93 & 55 \\
\hline \multicolumn{3}{|c|}{ 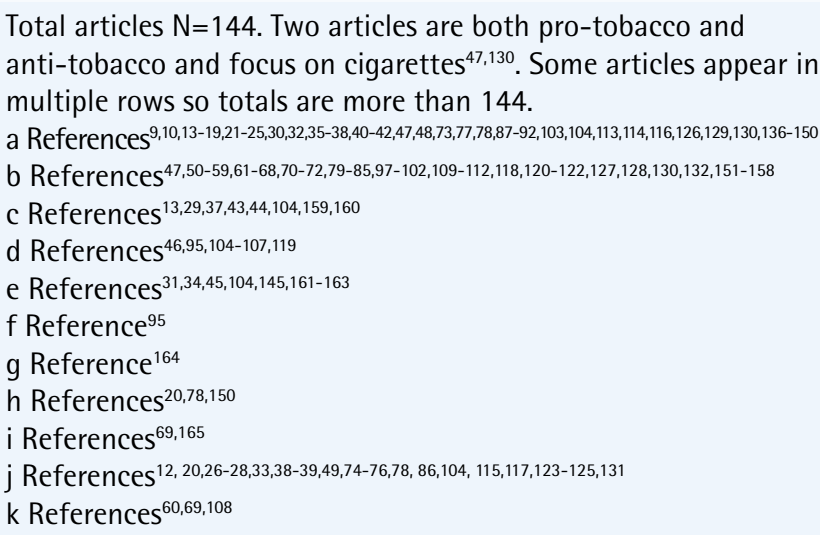 } \\
\hline
\end{tabular}

and none on pipe or roll-your-own tobacco.

Table 3 displays the 144 articles by vulnerable population. Articles were listed in multiple categories if more than one vulnerable sociodemographic group was included (e.g. lower SES women). The most prevalent category was race/ethnicity with $35 \%$ $(n=51)$ pro-tobacco and $21 \%(n=30)$ anti-tobacco.

\section{Table 3. Articles by tobacco focus and vulnerable population group}

\begin{tabular}{|c|c|c|}
\hline Population group & $\begin{array}{l}\text { Pro tobaceo } \\
\text { marketing }\end{array}$ & $\begin{array}{l}\text { Inti tobar } \\
\text { campaig }\end{array}$ \\
\hline $\begin{array}{l}\text { Women of reproductive } \\
\text { age }\end{array}$ & $14^{\mathrm{a}}$ & $7^{b}$ \\
\hline Pregnant women & $2^{c}$ & $4^{\mathrm{d}}$ \\
\hline Race and ethnicity & $50^{\mathrm{e}}$ & $30^{f}$ \\
\hline African American & 25 & 9 \\
\hline Hispanic/Latino & 7 & 6 \\
\hline Asian/Pacific Islander & 4 & 1 \\
\hline American Indian/Alaska & 1 & 2 \\
\hline $\begin{array}{l}\text { Native } \\
\text { Multiple }\end{array}$ & 17 & 13 \\
\hline Sexual minorities - LGBT & $4^{g}$ & $3^{\text {h }}$ \\
\hline Low socioeconomic status & $21^{i}$ & $15^{\mathrm{j}}$ \\
\hline Urban and rural areas & $15^{k}$ & $6^{1}$ \\
\hline Military/veterans & $6^{m}$ & $4^{n}$ \\
\hline Mental health disorders & $3^{\circ}$ & $2^{p}$ \\
\hline Medical co-morbidities & $1^{9}$ & 0 \\
\hline Total & 91 & 55 \\
\hline
\end{tabular}

Total articles $\mathrm{N}=144$. Two articles are both pro-tobacco and antitobacco ${ }^{47,130}$. Some articles appear in multiple rows so totals are more than 144. LGBT: Lesbian Gay Bisexual Transgender a References ${ }^{15,44,73,86-92,95,137,144,145}$

b References ${ }^{50,97-102}$

c References ${ }^{140,162}$

d References ${ }^{102,152,153,157}$

e References 9 ,10,12-49,136,137,139,141,150,159-161,163,166 : African

American $^{9,10,12-17,20-25,27-31,43-45,49,147,159}$; Hispanic/Latino ${ }^{24,27,32-35,141}$; Asian/Pacific Islander ${ }^{33,36,37,48}$; American Indian/Alaska Native ${ }^{38}$; Multiple Groups ${ }^{18,19,26,39-42,46,47,136,137,139,150,160,161,163,167}$

f References ${ }^{47,50-72,97,100,151,157,158,165}$ : African American ${ }^{61,62,66-69,72,97,151}$

; Hispanic/Latino ${ }^{59,60,66,70,157,158}$; Asian/Pacific Islander ${ }^{165}$; American Indian/Alaska Native ${ }^{50,64}$; Multiple Groups ${ }^{50-58,63,65,71,72}$

g References ${ }^{123-126}$

h References ${ }^{71,127,128}$

i References ${ }^{18,19,26-29,39,40,42,45,73-78,86,95,143,146,148}$

j References ${ }^{57,63,65,67,79-85,102,154-156}$

k References ${ }^{9,13,28,39,43,74,95,103-107,138,142,160}$

I References ${ }^{50,108-112}$

m References ${ }^{113-117,119}$

n References ${ }^{118,120-122}$

o References ${ }^{129-131}$

p References ${ }^{130,132}$

q Reference ${ }^{129}$ 


\section{Race and ethnicity}

Pro-tobacco marketing

One-third of the articles $(35 \%, n=51)$ examined pro-tobacco marketing to racial and ethnic minority populations. Most focused on AA, and far less on HL, API, multi-ethnic, 'minority' or 'non-White', populations. Surprisingly, almost no studies address tobacco marketing involving $\mathrm{AI} / \mathrm{AN}$ populations, which have the highest smoking prevalence in the US ${ }^{2,6,7}$.

\section{African Americans}

Several analyses describe the tobacco industry's history of targeting AAs with menthol cigarette marketing and donations to AA leadership organizations to improve its reputation in these communities ${ }^{9-14}$. Menthol cigarettes were marketed to AAs using culturally targeted messaging and images, implying potential healthful effects of menthol, building on cultural perceptions of mint as medicinal, and creating stronger menthol-flavoured cigarettes appealing to the taste preference of AA smokers ${ }^{9,10,15,16}$. Specific brands such as Newport and Kool targeted promotions to the AA community by featuring hip-hop culture and music and by placing menthol ads in AA magazines ${ }^{9,14,16}$. One of these marketing campaigns, Kool MIXX, was found to have violated the Master Settlement Agreement of 1998, which restricted targeted-marketing to youth ${ }^{16}$.

Tobacco advertisements were more prevalent in AA neighbourhoods ${ }^{17,18}$, at stores in AA neighbourhoods ${ }^{18-21}$, near schools with more AA students ${ }^{22}$, and in AA newspapers ${ }^{23}$ and magazines ${ }^{14,24,25}$. The density of tobacco retail outlets was higher in AA neighbourhoods than in White neighbourhoods ${ }^{26,27}$, and these stores were more likely to have discount promotions and lower prices for menthol cigarettes ${ }^{9,22}$. In New York and Missouri, tobacco retailer outlets were not only denser in poor and in African American communities, they were also located in close proximity to schools, demonstrating the utility of a potential ban on tobacco sales near schools to lower disparities in tobacco retail density ${ }^{28}$. Retailer density may have increased exposure to tobacco promotions. A national sample of retailers found more than twice the odds of price promotions and sale of flavoured cigars in AA neighbourhoods ${ }^{29}$. AA youth living near tobacco outlets reported higher intentions to smoke and greater number of days smoked $^{30}$.

Multiple studies among AAs showed associations between pro-tobacco marketing exposure and tobacco use $^{12,25,30,31}$. For example, pro-tobacco advertisement exposure was positively associated with purchasing cigarettes and smoking more cigarettes among AA smokers ${ }^{12}$. In a study of hospitalized smokers, White smokers were almost twice as likely to report exposure to e-cigarette ads (mostly through stores and the Internet) compared to AA smokers (mostly through radio and television); however, ad exposure was associated with e-cigarette use among AA smokers but not among White smokers ${ }^{31}$. In a more promising direction, one study showed that a decline in cigarette print advertising featuring AA models in AA magazines was associated with a decline in smoking initiation among $\mathrm{AAs}^{25}$.

\section{Hispanics/Latinos}

Targeting of HLs by the tobacco industry was based on segmentation by English/Spanish language comfort, acculturation, country of origin, and geographical region in the $\mathrm{US}^{32,33}$. Similar to strategies with AAs, research of industry documents indicated R. J. Reynolds Tobacco sponsored live music festivals with HLs, developed ties to HL leadership organizations like the US Hispanic Chamber of Commerce ${ }^{32}$ and advertised in specific HL communities such as along the US-Mexico border ${ }^{33}$.

Evidence of targeted marketing to HLs usually aggregated groups by language and general HL ethnicity rather than country of origin. Languagebased marketing appeared to be effective among HLs; e-cigarette usage was higher among English speakers with greater access to English language marketing, versus non-English speakers ${ }^{34}$. Some studies documented greater tobacco retailer density in HL compared to White neighbourhoods ${ }^{26-27}$ but other studies did not find differences for store advertising by neighbourhood $^{18}$ or for Spanish-language magazines relative to English-language magazines ${ }^{24}$. Menthol was also a marketing feature; one study found that tobacco ads published in Spanish-language women's magazines were more likely to be for menthol brands relative to ads in English-language women's magazines ${ }^{35}$.

\section{Asians/Pacific Islanders}

Research on advertising to API populations was limited and usually aggregated all API populations into one group. Industry documents revealed plans 
to market menthol cigarettes to Asian Americans because menthol cigarettes were popular among young women in several Asian countries of origin ${ }^{15,33}$. Industry targeting of API populations in the US focused on promoting shared values of cultural identity through smoking, including collectivism and hybrid Asian/Western values ${ }^{36}$. Philip Morris trained store distributors in cultural sensitivity and developed retail-marketing materials for Asian American store clientele ${ }^{36}$. Retail marketing surveillance in California revealed that the cheapest cigarettes cost even less in neighborhoods with a higher proportion of API populations ${ }^{37}$. Studies on the association of marketing with tobacco use were limited for these populations. Among Asian American youth, receptivity to tobacco marketing was associated with regular smoking ${ }^{31}$.

\section{American Indians and Alaska Natives}

No study was identified on pro-tobacco marketing specifically directed toward AI/AN populations. One study analyzed ways in which the tobacco industry used AI imagery (e.g. the Natural American Spirit headdress), and marketed tobacco as 'natural' and 'traditional' ${ }^{38}$. However, this study was about the use of AI imagery rather than about marketing directed at this population.

\section{$\underline{\text { Multi-ethnic }}$}

Several studies examined tobacco retailer density related to neighbourhood ethnicity and income. Density of retailers selling tobacco was positively associated with the proportion of AA residents, negatively associated with the proportion of API residents, and not associated with HL residents ${ }^{39}$. Greater tobacco outlet density was found in areas categorized generally as predominantly non-White or minority populations that either included multiple groups or did not define ethnicity ${ }^{40,41}$. This density link may have been related, in part, to income. One study found more outdoor tobacco advertisements in neighbourhoods with larger proportions of nonWhites, which also corresponded with lower income areas ${ }^{40}$. In that study, the finding may have been due to laws restricting exterior signage in higher income areas ${ }^{40}$. Studies that examined advertising and promotions within stores found differences in communities with more multi-ethnic populations. For example, another study found higher prices of discount and premium cigarettes in stores in areas with more minority residents, although there were no differences in menthol prices ${ }^{41}$. More African American and HL smokers and more lower-income smokers reported exposure to in-store tobacco marketing compared to White Non-Hispanic and higher income smokers in Nebraska ${ }^{42}$.

Few studies have focused on racially and ethnically targeted pro-tobacco marketing of products other than cigarettes, as described in Table 3. Little cigar or cigarillo advertisements were more prevalent in stores in AA neighbourhoods ${ }^{13,43}$. The price of a single Swisher Sweet cigarillo was significantly lower in AA neighbourhoods than in White neighbourhoods ${ }^{37}$. Tobacco companies marketed menthol little cigars to AAs by featuring hip-hop culture and music ${ }^{44}$. Two cross-sectional studies examined exposure to e-cigarette marketing among $\mathrm{AAs}^{45}$. AA neighbourhoods had more e-cigarette advertising on store exteriors ${ }^{45}$. One study found that AAs reported more e-cigarette advertising exposure from radio or television than Whites, and e-cigarette advertising was associated with e-cigarette use among $\mathrm{AAs}^{31}$. One study of retail outlets found that smokeless-tobacco (ST) advertisements were most prevalent in AA and Asian neighbourhoods ${ }^{46}$.

Only two studies of associations between protobacco marketing exposure and tobacco use explicitly examined racial/ethnic variation in the strength of those associations ${ }^{30}$. One study found that smoking on TV and pro-tobacco advertisements in stores were associated with adolescent smoking susceptibility but the strength of this relationship did not differ by race/ethnicity ${ }^{30,31}$. The other study found that e-cigarette advertisement exposure was associated with e-cigarette use among AAs but not among Whites ${ }^{31}$.

Comparisons across studies were difficult because most studies focused on one type of marketing and one population or community. Measures of protobacco marketing exposure among respondents varied widely, from self-reported recall to media receptivity measures such as having a favourite brand or willingness to use a tobacco promotional item. Despite these methodological issues, most of these studies consistently found positive associations between tobacco marketing exposure/receptivity and smoking behaviour ${ }^{47-49}$. 


\section{Anti-tobacco campaigns}

About one-fifth $(21 \%, \mathrm{n}=30)$ of the articles focused on anti-tobacco campaigns for racial/ethnic minority populations. Most population-based studies of awareness and effectiveness of anti-tobacco campaigns found similarities, rather than differences, across racial/ethnic groups ${ }^{50-54}$. For example, exposure to the 'truth' campaign, a major national youth prevention campaign, was associated with lower risk of smoking initiation, lower intentions to smoke in the next year, and more negative attitudes about tobacco companies across racial/ethnic groups $\mathrm{s}^{53,55}$. Across state antitobacco campaigns, higher campaign exposure was associated with decreased odds of smoking across racial/ethnic groups ${ }^{54}$.

However, some anti-tobacco media campaigns showed differential effects across racial/ethnic groups. For example, awareness of the ' $\mathrm{EX}$ ' mass media campaign was associated with quit attempts among AA adult smokers, but not among White or HL smokers ${ }^{56,57}$. A multi-channel campaign promoting the 2006 Nicotine Patch Program had similar effects across racial/ethnic groups in raising awareness, but HL and AA adult smokers were more interested in the program than were White and API smokers ${ }^{58}$.

There was limited research on differential responses to anti-tobacco message themes and modalities ${ }^{59-62}$. Graphic and emotional anti-smoking ads in one study were associated with quit attempts among AA and White smokers, but not among HL smokers ${ }^{63}$. A study among $\mathrm{AI} / \mathrm{ANs}$ found reactions of anger, sadness and worry to graphic warning labels depicting children but did not compare reactions among other populations ${ }^{64}$. Another study found that non-White participants were more likely to respond to online ads for cessation treatments than to traditional media ${ }^{65}$. A general media campaign promoted more calls to the Massachusetts quitline among White smokers, while targeted provider outreach was more effective at increasing quitline referral rates among AAs and $\mathrm{HLs}^{66}$. These differences identified a need to target outreach efforts and message design to specific audiences but were limited in comparing groups.

Culturally targeted messages incorporating cultural values and beliefs were explored in several studies. Messages based on cultural beliefs about smoking among low-income African American smokers were more likely to contribute to intention to quit compared to non-targeted messages ${ }^{67,68}$. A social media-based video campaign for Somali American youth used youth-driven messaging focusing on social and religious norms about tobacco use ${ }^{69}$. Messages, framing and channels of delivery were assessed for Spanish-speaking smokers to guide them to an online cessation program (Become an Ex) ${ }^{70}$; viewers were more likely to click on website banners on the Spanish version of Yahoo compared to other websites, and on banner ads with themes of loss-frame over gain-frame, familism rather than fatalism, and ads targeted to characteristics such as language and dress compared to other ads. In a study that compared the ethnicity of viewers with the intended ethnicity of anti-tobacco ads, the viewers liked the ads more if they thought the intended audience matched their own ethnicity ${ }^{71}$.

Perception and recall of anti-smoking advertisements also differed by race/ethnicity. HL compared to White adolescents reported less exposure to anti-tobacco advertisements at schools and sporting events ${ }^{72}$. AA adolescents recalled fewer television and poster antismoking advertisements than White adolescents but recalled more ads at movies and live sporting events.

\section{Low socioeconomic status (SES)}

\section{Pro-tobacco marketing.}

Studies of tobacco marketing to low SES populations represented $15 \%(n=22)$ of the articles. Most of these studies analyzed tobacco industry documents or described point-of-sale marketing in low-SES neighbourhoods.

Tobacco companies historically identified 'working class,' 'less-educated' and 'present-oriented' consumers as an important market ${ }^{73}$. For instance, an R.J. Reynolds project in 1976 distributed cigarette coupons with food stamps to 'welfare mothers'. Initially, tobacco companies developed cigarette brands specifically for lower SES consumers, but the approach shifted over time to include these demographics in marketing for established brands (e.g. Marlboro $)^{73}$.

Higher tobacco retailer density ${ }^{19,27}$, lower tobacco prices $^{37}$, and more tobacco marketing ${ }^{19,40,74-76}$ were found in lower SES than in higher SES communities. Stores in lower income neighbourhoods also had more ads for menthol cigarettes ${ }^{18}$. It is unclear whether this indicated targeting to racial/ethnic minorities or to low-SES populations, as these vulnerabilities 
often co-occurred in the same neighbourhoods ${ }^{19}$. Cigarette prices were lower in stores near public schools compared with private schools ${ }^{77}$. Proximity to tobacco retailers was important because smokers living in high poverty areas close to tobacco retailers were less likely to quit smoking and had lower processation attitudes than those living farther away or in higher SES areas ${ }^{78}$.

\section{Anti-tobacco campaigns}

Studies of anti-tobacco campaigns to low SES populations represented $10 \%(n=15)$ of the studies identified. Several examined message design, finding that advertisements using strong negative emotions, testimonials or graphic imagery were more effective in motivating low-SES smokers to quit compared to high-SES smokers ${ }^{63,79-81}$. Viewing a web-based anti-smoking ad changed implicit attitudes toward smoking among smokers with less formal education ${ }^{82}$. However, anti-smoking campaigns that stigmatized smoking had a boomerang effect in which exposure significantly lowered their cessation intentions ${ }^{37}$. A qualitative study on anti-smoking messages found culturally-targeted messages were more appealing to lower income smokers than other messages ${ }^{67}$. However, these low-SES smokers also reported scepticism about cessation messages and barriers to quitting related to stress, social contexts, and addiction $^{83}$. Among blue collar construction workers, smoking cessation ads that emphasized family and work and presented smoking harms in the context of work hazards were more appealing than other messages ${ }^{84}$. Only a few studies examined avenues for reaching lower SES populations. Two of these studies found higher awareness of anti-tobacco campaigns among individuals or neighbourhoods with higher formal education ${ }^{57,85}$. One study that examined channels to reach populations found that online ads promoting cessation treatments reached a higher percentage of smokers with a high school education or less compared to more traditional media channels ${ }^{65}$.

\section{Women of reproductive age and pregnant women}

Pro-tobacco marketing

Women of reproductive age (average 18-51 years old) were targeted by tobacco companies, as described in $10 \%(n=14)$ of our pro-tobacco articles. They are a vulnerable population because of the complications of tobacco use during pregnancy if they begin using tobacco and then are unable to quit. The companies used multiple methods, including female-focused advertising campaigns, product/package design, and targeting specific subgroups of women. One of the first industry marketing efforts, in the 1920s, marketed Lucky cigarettes as an appetite suppressant ${ }^{86,87}$. In the 1960s, PM launched Virginia Slims, one of the first American female-marketed cigarette brands, with themes about money and materialism ${ }^{88}$. Other female-focused cigarette brands appeared during the $1980-90 \mathrm{~s}^{73,86,87,89,90}$. Each brand reflected a specific female image or niche: Dakota (young women with blue-collar jobs, street-smarts, and toughness); Virginia Slims (stylish and status conscious women) ) $^{73}$ and Chelsea (thrifty women who had less formal education $)^{86}$. Tobacco companies also targeted military wives, inner-city minority women, and pricesensitive women ${ }^{86}$. Military wives were perceived to be a captive audience of young women with lower income, less formal education and geographical isolation who could form lifelong brand loyalties and could produce word-of-mouth advertising on the military base ${ }^{86}$. Inner-city AA women were perceived as being of lower income, concerned with present needs, having extended family obligations, and being price-sensitive. To reach this group, R.J. Reynolds reduced pack prices at retail, advertised in locations such as clubs, bus stops, and beauty salons, and distributed free fingernail decals and earrings with Salem logos. Tobacco companies marketed cigarettes as a small indulgence to compensate for personal sacrifices among price-sensitive women ${ }^{86}$.

Analysis of tobacco documents identified product design features that were attractive to women and appealed to their social and health concerns, including small, colourful packs, slim cigarettes, lower tobacco content, milder tobacco, slower burn rate, flavours, and low side-stream emissions to decrease secondhand smoke $^{89}$. Women also preferred cigarette packs with overtly female designs and flavours, and associated them with popularity, attractiveness, slimness, glamour, and lower health risks ${ }^{87}$.

Several studies assessed the reactions of adolescent and adult women to tobacco advertisements with various images and themes. The advertising campaign for Camel No. 9, which was launched in 
2007 , was followed by a $10 \%$ rise in adolescent girls who nominated a favourite cigarette advertisement, compared to earlier years. Nomination of a favourite ad was a significant predictor of tobacco experimentation in this population ${ }^{90}$. Adolescent girls also rated femalevalenced ads ${ }^{91}$ and ads with relaxation themes ${ }^{92}$ more highly than other ads, perhaps because these ads generated self-relevance and positive affect. Femalefocused marketing also used themes of thinness and popular celebrity usage ${ }^{89,93,94}$.

Although most tobacco marketing research focused on cigarettes, research on tobacco industry documents indicated that the launch of snus in the 2000s was partially an effort to attract urban women to $\mathrm{ST}^{95}$. Emerging products such as e-cigarettes, snus, and dissolvables were identified in documents research as potentially appealing to women ${ }^{95,96}$.

\section{Anti-tobacco campaigns}

Anti-smoking media campaigns for women of reproductive age comprised $5 \%(n=7)$ of the articles; and $3 \%(n=4)$ focused on pregnant women, usually reporting effects of specific campaigns. For example, 'One Tiny Reason to Quit' ran in 2009 and 2011, targeting pregnant AA women with gain-frame messages that offered benefits of quitting ${ }^{97}$. The campaign was disseminated via multiple channels in high-risk neighbourhoods, community venues and AA media outlets. During the campaign, the proportion of pregnant AA women who called the quitline increased.

Several types of anti-tobacco messages were effective among women. Both high-fear (e.g. risk of death or tracheotomy) and low-fear arousal messages (e.g. tobacco industry is deceptive, smokers appear foolish) resulted in lower intentions to smoke, more negative attitudes toward smoking, greater susceptibility to anti-smoking ads, and more negative beliefs about the acceptability of smoking among women ${ }^{98}$. Empathy appeals (campaigns that represented someone's pain, interpersonal relationships, or emotions) were more effective for women than for men, but fear appeals were equally effective for both sexes ${ }^{99}$. Ads that emphasize shortterm consequences of smoking (e.g. social rejection, appearance) were more effective at reducing smoking behaviour and increasing intentions to quit among women, but messages with long-term consequences (e.g. disease, death) were more effective at reducing intentions to start smoking in women ${ }^{100}$. Online ads about health effects of smoking were more effective among women than ads that empowered viewers or suggested ways to quit smoking ${ }^{101}$. Among low-SES smoking mothers, health messages about protecting children from secondhand smoke were associated with intentions to quit when the source of the message was personal (i.e. friends, family) or a physician, while health messages from dentists were associated with lower child tobacco smoking exposure ${ }^{102}$.

\section{Urban/rural areas}

\section{Pro-tobacco marketing.}

Geographically defined communities considered vulnerable to tobacco industry marketing included inner city urban and rural communities, analyzed in $10 \%(n=15)$ of the studies. The tobacco industry identified urban 'focus' communities that were predominantly low-income and AAs with high menthol sales as an important part of their strategy to recover declining cigarette sales in the US ${ }^{9}$. Marketing practices included contracts with these retailers to ensure prominent product displays, cigarette packaging appealing to smokers, discount programs to increase retailer profits in exchange for control over how stores offer products, and urban life-oriented campaigns to increase menthol cigarette sales. Urban census tracts also were more likely to have tobacco ads within 500 feet of schools, playgrounds and churches, in violation of the Master Settlement Agreement ${ }^{74}$.

Rural youth reported more cigarette smoking and more exposure to retail tobacco advertising than urban youth ${ }^{103}$. However, sociodemographic factors, cigarette taxes, and tobacco ad exposure did not entirely explain urban/rural disparities ${ }^{104}$. A qualitative study of smokeless tobacco use among rural male youth found that product characteristics (i.e. brands, flavors, and packaging) encouraged continued ST use, while availability of flavors and seasonal offerings encouraged experimentation ${ }^{105}$.

Rural areas were targeted by smokeless tobacco (ST) marketing aimed at low-SES men. Industry documents showed that R.J. Reynolds reached rural, low-income males through ST sampling, television commercials and sponsorship at fishing, rodeo, and baseball, events ${ }^{95}$. Qualitative research suggested that marketers of ST capitalized on perceptions of masculinity in rural communities to reinforce 
initiation and continued ST use ${ }^{106}$. Focus group and interview participants in Appalachian Ohio confirmed the ease of obtaining ST and how packaging and advertisements reflected male cultural standards of their communities ${ }^{106}$. After the Family Smoking Prevention and Tobacco Control Act of 2009 was enacted, there was a reduction in the frequency of tobacco ads at retail outlets. However, the proportion of stores advertising ST did not significantly change and the number of ST brands being advertised doubled between baseline and follow-up ${ }^{107}$.

\section{Anti-tobacco campaigns}

We identified anti-tobacco campaigns toward urban or rural areas in $4 \%(n=6)$ of the studies. Rural youth recalled and perceived ads differently from more urban populations. Rural youth in Indiana were less likely to recall anti-tobacco media messages than suburban adolescents ${ }^{108}$. Nevertheless, anti-tobacco media campaigns were able to reach rural communities. The national 'truth' campaign expanded to reach rural and low-population-density area youth by purchasing local broadcast media. Confirmed awareness increased from $40 \%$ to about $70 \%$ among youth in those rural media markets ${ }^{109}$. Rural youth were highly receptive to 'truth' advertisements, though never smokers were more receptive than ever smokers ${ }^{109}$. In 'The Plain Truth' campaign, TV and radio ads depicting graphic health harms from tobacco were highly recalled and perceived as effective by both American Indian and White youth in the Northern Plains region of the US $^{50}$. Response to ads may have differed by smoking status of the youth. Rural high school students who used tobacco were more likely to perceive the national 'truth' campaign as ineffective and to hold negative perceptions of anti-tobacco messages compared to non-users ${ }^{110}$.

Among rural adults, local media, technology, billboards, and print, were considered more effective than state-wide media channels to promote secondhand smoke and smoke-free policies ${ }^{111}$. Print media were an important source of exposure to anti-tobacco campaigns in rural populations. Print messages that contained negative emotional tone, loss framing, appeals to religiosity and shifting focus away from smokers were perceived as effective strategies for promoting support for smoke-free policies in rural communities $^{112}$.

\section{Military or veterans}

\section{Pro-tobacco marketing.}

A few studies $(4 \%, n=6)$ documented the pervasiveness of pro-tobacco promotions in military life. Soldiers reading military newspapers were exposed to an over-representation of pro-tobacco content and an under-representation of tobacco control messages ${ }^{113}$. Tobacco advertising in The Military Times magazine, widely read by military personnel, had no cigarette or other combustible tobacco ads but frequently contained ST ads. On military bases, tobacco was sold at substantially lower prices than at public retail outlets $^{114}$.

In the 1980-90s industry documents identified 1400 tobacco-sponsored events for military personnel in the US and abroad, until this form of event marketing was restricted by the Master Settlement Agreement $^{115}$. These market plans revealed strategic efforts to increase tobacco sales volume among military personnel by selling through military outlets and attracting young men of a specific lifestyle and SES who could carry tobacco use into civilian life ${ }^{116}$. Marketing plans included in-store merchandising, event sponsorship, development of brands appealing to military personnel, and legislation protecting these tobacco promotions. A case study of the Gulf War (1990-91) demonstrated use of industry-sponsored free samples, direct mail, functional items with brand names on them (e.g. an item of clothing with a cigarette brand name on it), and tobacco-sponsored events that assisted communication with families and welcomed troops home. As a result, tobacco companies were perceived as benefactors, often receiving positive support from military authorities ${ }^{117}$.

\section{Anti-tobacco campaigns}

Smoking was more prevalent among enlisted junior personnel than the general population, and nearly half reported that they began smoking after enlisting ${ }^{118}$. However, few studies analyzed efforts to reduce tobacco use in this population $(3 \%, n=4)$. Antitobacco articles received limited coverage in military magazines compared to other health topics ${ }^{119}$. A focus group study of Air Force and Army personnel identified themes that could deter smoking in this population: smoking can lead to early discharge, lessen the ability to fight, reduce productivity, and ability to lead others. However, messages typically 
used with young adults about tobacco industry manipulation and health effects had less support ${ }^{118}$. A different focus group study of US military personnel examined myths about smoking and found that all participants believed that tobacco served military needs by reducing stress, fitting in with others and helping them take breaks, despite known effects of tobacco on fitness ${ }^{120}$. Media coverage of the hazards of secondhand smoke helped pass a smoking ban in Navy submarines ${ }^{121}$. Among Air Force trainees ${ }^{122}$ exposure to existing anti-tobacco advertisements developed for the general population led to increased perceived harm and reduced intentions to use tobacco products. Among these ads, those that portrayed the negative effects of tobacco on health or sexual performance and revealed tobacco industry manipulations were most effective.

\section{Sexual minorities (LGBT)}

\section{Pro-tobacco marketing}

Only $3 \%(n=4)$ of the articles focused on pro-tobacco marketing to LBGT populations; with most drawn from documents research of industry marketing practices. Philip Morris first placed ads in a national LGBT magazine in 1992. Since then tobacco advertising in weekly LGBT newspapers and magazines is fairly common ${ }^{123}$. Most ads featured sexual ambiguity rather than overtly LGBT individuals ${ }^{123,124}$. For example, Philip Morris created ads with a man and woman when targeting the general public, but added a second man or woman to the ad when targeting the LGBT community $^{123}$. In addition to tobacco ads (typically large and image-based) and smoking cessation ads (typically small and text-based), LGBT periodicals also contained numerous images of celebrities smoking ${ }^{124}$.

Tobacco companies also attempted to gain loyalty from the LGBT community and improve their corporate image by: donating to HIV/AIDS causes; publicizing their anti-discrimination, antiharassment, and diversity-awareness business policies ${ }^{123}$; sponsoring performing arts; and giving away tobacco samples and coupons at events in LGBT communities ${ }^{125}$. In a focus group study, LGBT individuals perceived the tobacco industry targeting as a form of social acceptance and an opportunity to increase their visibility to the general population ${ }^{126}$.

\section{Anti-tobacco campaigns}

Only $2 \%$ of the studies focused on anti-tobacco campaigns for LGBT populations. Awareness of ads promoting smoking cessation was similar among LGBT individuals and their heterosexual counterparts ${ }^{127}$. In a study that compared reactions to anti-tobacco ads targeting AA, HL and LGBT populations, support for anti-tobacco messages was lowest for the LGBT themed ads but higher if someone self-identified as LGBT compared to those who did not ${ }^{71}$. A 2013-14 anti-smoking educational campaign (Break $U p$ ) for LGBT individuals in Los Angeles County, featured graphic advertisements online and in bars, clubs, and gyms in areas of the county with the highest concentration of businesses that service the LGBT community. Approximately one-third of LGBT participants were aware of the campaign. Among those aware of it, more than one-third had discussed the campaign with someone else, while one-fourth shared the campaign on social media. Awareness of the campaign among LGBT smokers was associated with seriously thinking about quitting and ever having taken steps to quit smoking; however, awareness of the campaign was not associated with smoking cessation $^{128}$.

\section{Mental health disorders}

\section{Pro-tobacco marketing.}

Only $2 \%$ of the articles focused on pro-tobacco marketing to people with mental illness. Tobacco industry documents revealed strategies for marketing cigarettes to people who were homeless or had serious mental illness, and industry alliances with providers of services to these populations ${ }^{129}$. Smoking among patients in substance-use treatment was associated with high exposure and receptivity to tobacco advertisements ${ }^{130}$. A San Francisco study also found higher exposure, with a twofold greater tobacco retailer density in neighbourhoods of smokers with severe mental illness compared to the general population ${ }^{131}$. In that study, greater retail availability was associated with poorer mental health, greater nicotine dependence and lower self-efficacy for quitting among residents with severe mental illness.

\section{Anti-tobacco campaigns}

We identified only one article examining smokingrelated health messaging among people with mental 
illness ${ }^{132}$. That study found that young people with psychotic disorders responded favourably to both picture and video health warnings, and that such media messages can be highly effective among people with psychosis.

\section{DISCUSSION}

This review highlighted important gaps in the research on pro-tobacco marketing and anti-tobacco campaigns for vulnerable populations in the US. These gaps included certain types of tobacco products, at-risk populations, and corresponding marketing strategies.

Almost all of the pro-tobacco marketing literature focused on cigarettes or more generally on 'tobacco' as a general product, followed in frequency by cigars/ little cigars and e-cigarettes. One pro-tobacco study was found on hookah/waterpipe, one on snus and none on pipe or roll-your-own tobacco. In the past five years some analyses have emerged for e-cigarettes. No tobacco prevention or cessation campaign was identified on cigars/little cigars, e-cigarettes, smokeless tobacco, snus, pipe or roll-your-own tobacco. These gaps may reflect the market share of cigarettes but provides little evidence to inform campaigns to prevent use of emerging tobacco products.

There were also notable gaps for certain populations. Most studies on pro-tobacco marketing involved women of reproductive age, AAs, people with low SES, and inner city urban or rural populations. Among these studies, several addressed the intersections of vulnerable groups defined by race, SES, and urban neighbourhood. However, there were very few studies on pro-tobacco marketing aimed at sexual minorities, $\mathrm{AI} / \mathrm{ANs}$ and people with medical co-morbidities or mental illness. These populations could be analyzed using tobacco industry documents and more current survey research. For example, a recent analysis of industry documents revealed that tobacco companies targeted $\mathrm{AI} / \mathrm{AN}$ populations with price reductions, coupons, giveaways, charitable sponsorships, and nonevidence-based youth smoking prevention programs, as well as capitalizing on the sovereign status of Tribal lands, stores, and casinos, to sell cigarettes tax-free ${ }^{133}$. In the anti-tobacco literature on tobacco prevention and cessation campaigns, there were major population gaps for pregnant women, LGBT populations, APIs, $\mathrm{AI} / \mathrm{ANs}$, military/veterans, and/or those with mental health or other medical co-morbidities, despite the high tobacco related risks for these populations. The evidence for tailored messages and targeted channels for these specific high-risk populations would be useful but it is sparse. Additional empirical research on these populations is recommended since such data may be helpful for understanding disparities in tobacco use and developing more effective tobacco control strategies.

The studies on pro-tobacco marketing strategies documented common industry tactics that segmented consumers and optimized appeal and uptake of tobacco products. These tactics included designing products, packaging and advertisements to appeal to population niches, reducing prices, advertising in sociodemographically targeted outlets and locations, and donating to leadership organizations to gain loyalty from vulnerable communities. Research on the methods of targeted anti-tobacco campaigns found that specific messages tailored for subgroups, when used, appeared to be more salient and acceptable to vulnerable population groups. However, broad-reach campaigns were also found to be effective in reaching across subpopulations when combined with strategic placement in population-specific channels and media. Additional research is needed to understand geographical and SES variations that could improve access to and understanding of campaign messages as well as the impacts, reach and limitations of general campaigns, compared to targeted campaigns.

Well-designed mass marketing prevention and cessation campaigns using culturally appropriate media, languages, channels and message designs are needed in combination with tobacco control policies to counter pro-tobacco marketing and reduce tobacco use disparities ${ }^{134}$. The passage of the Family Smoking Prevention and Tobacco Control Act in 2009 granting the Food and Drug Administration the authority to regulate tobacco products provided new opportunities for a combination of communication campaigns and regulations to prevent the harms of tobacco product use in vulnerable populations. For example, in 2015 , the Food and Drug Administration launched 'Fresh Empire', a national campaign for at-risk multicultural youth who identified with hip-hop culture, specifically AA, HL and API youth. In 2016, it launched 'This Free Life', a public education campaign to prevent and reduce tobacco use among LGBT young adults. These campaigns are taking place at the same time as 
evolving federal regulatory efforts to improve warning labels and to limit flavours (other than menthol and tobacco flavours) and e-cigarettes. Existing federal regulations limit claims of 'light', 'mild', and 'low-tar' products, sales to youth, tobacco brand sponsorship, branding of functional items and services, and free samples. State regulations and legal settlements have provided additional restrictions on tobacco marketing not yet found at the federal level.

Additional tobacco control policies suggested by our literature review can help lessen the impact of tobacco on vulnerable groups. For example, tobacco signage, displays, discounts and sales in retail outlets can be limited to shelving separated from public view, to reduce exposure to non-tobacco customers. The geographically targeted retailer density and point-of-sale marketing of tobacco products to vulnerable communities could be further limited with retail licensing that charges licensing fees that reduce the number of stores selling tobacco and restrict the location or visibility in proximity to schools, parks, and mental hospitals ${ }^{135}$. Tobacco advertising in magazines can reach very specific populations of tobacco users and non-users with persuasive characteristics that resonate with the viewers. A restriction on print advertising would limit this type of targeted effort. Tobacco advertising on Internet sites also has the potential to reach both broad and targeted audiences regardless of age or tobacco use status. This reach could be diminished with advertisements limited to sites that use gateways that stop viewers unless they can demonstrate that they are at least 21 years of age and use tobacco. Finally, requiring plain packaging also could prevent the tobacco industry from using design features that attract vulnerable populations.

Although this literature review focused on findings from research conducted in the United States, similar anti-tobacco and pro-tobacco strategies, most likely, are being used in other countries and continue to impact smoking prevalence among vulnerable populations. The gaps and challenges identified here can provide insights into potential areas of focus for countries working under the Framework Convention on Tobacco Control worldwide (which the US has not yet ratified) and with high risk populations defined by minority, geographical, SES, military and medical status.

\section{Strengths and limitations}

The types of research studies included qualitative studies, observational studies identifying patterns of exposure, awareness, and attitudes at the population level, point-of-sale marketing studies, documents research revealing industry marketing strategies, and laboratory studies comparing media perceptions and effects. We may have missed literature not covered in our data bases, such as advertising studies from predominantly business databases. The nature of our search process yielded results that made comparisons difficult across populations or types of campaigns, and limited our ability to address how targeted marketing affects vulnerable populations differentially. At the same time, this heterogeneity revealed a wide array of marketing practices that informed this analysis. Many studies lacked detail that could lead to countermarketing recommendations due to aggregating groups like API or LGBT. Research on retail outlets did not always specify the SES or racial/ethnic makeup of local communities. Comparable measures and sampling designs would facilitate comparisons between studies in the future. Finally, few data existed on the use of new marketing channels of mobile and social media platforms for targeting vulnerable groups.

\section{CONCLUSIONS}

This study provides an extensive review of literature from multiple disciplines involved in marketing research. It identifies several patterns of pro-tobacco marketing or anti-tobacco campaigns that can be used to design regulatory and communication strategies to prevent smoking, improve cessation, and reduce health disparities. However, there are serious gaps in research on marketing affecting some of the most vulnerable populations. Most notably, there is a need for studies on anti-tobacco campaign strategies reaching these groups. These gaps need to take priority in future planning efforts at the local, state, and national level.

\section{REFERENCES}

1. U.S. Department of Health and Human Services. The role of the media in promoting and reducing tobacco use. Tobacco Control Monograph 19. Bethesda, MD: U.S. Department of Health and Human Services, National Institutes of Health, National Cancer Institute; 2008. NIH Publication Number 07-6242. 
2. US Department of Health \& Human Services. The Health Consequences of Smoking - 50 Years of Progress: a report of the Surgeon General. Atlanta, GA: U.S. Department of Health and Human Services, Centers for Disease Control and Prevention, National Center for Chronic Disease Prevention and Health Promotion, Office on Smoking and Health; 2014.

3. Kreuter MW, Lukwago SN, Bucholtz RD, Clark EM, Sanders-Thompson V. Achieving cultural appropriateness in health promotion programs: targeted and tailored approaches. Health Educ Behav. 2003;30(2):133-146. doi:10.1177/1090198102251021

4. Kreuter MW, Wray RJ. Tailored and targeted health communication: strategies for enhancing information relevance. Am J Health Behav. 2003;27 Suppl 3:S227-S232.

5. U.S. National Cancer Institute. A socioecological approach to addressing tobacco-related health disparities. National Cancer Institute Tobacco Control Monograph 22. NIH Publication No. 17-CA-8035A. Bethesda, MD: U.S. Department of Health and Human Services, National Institutes of Health, National Cancer Institute; 2017.

6. Odani S, Armour BS, Agaku IT. Racial/ethnic disparities in tobacco product use among middle and high school students - United States, 2014-2017. MMWR Morb Mortal Wkly Rep. 2018;67(34):952-957. doi:10.15585/mmwr.mm6734a3

7. Jamal A, Phillips E, Gentzke AS, et al. Current cigarette smoking among adults - United States, 2016. MMWR Morb Mortal Wkly Rep. 2018;67(2):53-59. doi:10.15585/mmwr.mm6702a1

8. US Department of Health \& Human Services. Preventing tobacco use among youth and young adults: a report of the Surgeon General. Atlanta, GA: U.S. Department of Health and Human Services, Centers for Disease Control and Prevention, National Center for Chronic Disease Prevention and Health Promotion, Office on Smoking and Health; 2012.

9. Cruz TB, Wright LT, Crawford G. The menthol marketing mix: targeted promotions for focus communities in the United States. Nicotine Tob Res. 2010;12 Suppl 2:S147-S153. doi:10.1093/ntr/ntq201

10. Gardiner PS. The African Americanization of menthol cigarette use in the United States. Nicotine Tob Res. 2004;6 Suppl 1:S55-S65. doi:10.1080/14622200310001649478

11. Lee YO, Glantz SA. Menthol: putting the pieces together. Tob Control. 2011;20 Suppl 2:ii1-ii7. doi:10.1136/tc.2011.043604

12. Robinson CD, Muench C, Brede E, et al. Pro-tobacco advertisement exposure among African American smokers: An ecological momentary assessment study. Addict Behav. 2018;83:142-147. doi:10.1016/j.addbeh.2017.10.015

13. Roberts ME, Berman ML, Slater MD, Hinton A, Ferketich AK. Point-of-sale tobacco marketing in rural and urban Ohio: Could the new landscape of tobacco products widen inequalities? Prev Med. 2015;81:232-235. doi:10.1016/j.ypmed.2015.08.024
14. Richardson A, Ganz O, Pearson J, Celcis N, Vallone D, Villanti AC. How the industry is marketing menthol cigarettes: the audience, the message and the medium. Tob Control. 2015;24(6):594-600. doi:10.1136/tobaccocontrol-2014-051657

15. Anderson SJ. Marketing of menthol cigarettes and consumer perceptions: a review of tobacco industry documents. Tob Control. 2011;20 Suppl 2:ii20-ii28. doi:10.1136/tc.2010.041939

16. Hafez N, Ling PM. Finding the Kool Mixx: how Brown \& Williamson used music marketing to sell cigarettes. Tob Control. 2006;15(5):359-366. doi:10.1136/tc.2005.014258

17. Moreland-Russell S, Harris J, Snider D, Walsh H, Cyr J, Barnoya J. Disparities and menthol marketing: additional evidence in support of point of sale policies. Int J Environ Res Public Health. 2013;10(10):4571-4583. doi:10.3390/ijerph10104571

18. Widome R, Brock B, Noble P, Forster JL. The relationship of neighborhood demographic characteristics to pointof-sale tobacco advertising and marketing. Ethn Health. 2013;18(2):136-151. doi:10.1080/13557858.2012.701273

19. Seidenberg AB, Caughey RW, Rees VW, Connolly GN. Storefront cigarette advertising differs by community demographic profile. Am J Health Promot. 2010;24(6):e26-e31. doi:10.4278/ajhp.090618-quan-196

20. Kirchner TR, Villanti AC, Cantrell J, et al. Tobacco retail outlet advertising practices and proximity to schools, parks and public housing affect Synar underage sales violations in Washington, DC. Tob Control. 2015;24(e1):e52-e58. doi:10.1136/tobaccocontrol-2013-051239

21. Feighery EC, Schleicher NC, Boley Cruz T, Unger JB. An examination of trends in amount and type of cigarette advertising and sales promotions in California stores, 2002-2005. Tob Control. 2008;17(2):93-98. doi:10.1136/tc.2007.022046

22. Henriksen L, Schleicher NC, Dauphinee AL, Fortmann SP. Targeted advertising, promotion, and price for menthol cigarettes in California high school neighborhoods. Nicotine Tob Res. 2012;14(1):116-121. doi:10.1093/ntr/ntr122

23. Cohen EL, Caburnay CA, Rodgers S. Alcohol and tobacco advertising in black and general audience newspapers: targeting with message cues? J Health Commun. 2011;16(6):566-582. doi:10.1080/10810730.2011.551990

24. Landrine H, Klonoff EA, Fernandez S, et al. Cigarette advertising in Black, Latino, and White magazines, 1998-2002: an exploratory investigation. Ethn Dis. 2005;15(1):63-67.

25. Trinidad DR, Blanco L, Emery SL, Fagan P, White MM, Reed MB. Associations between cigarette print advertising and smoking initiation among African Americans. J Racial Ethn Health Disparities. 2017;4(3):515-522. doi:10.1007/s40615-016-0253-9

26. Loomis BR, Kim AE, Goetz JL, Juster HR. Density of 
tobacco retailers and its association with sociodemographic characteristics of communities across New York. Public Health. 2013;127(4):333-338. doi:10.1016/j.puhe.2013.01.013

27. Schneider JE, Reid RJ, Peterson NA, Lowe JB, Hughey J. Tobacco outlet density and demographics at the tract level of analysis in Iowa: Implications for environmentally based prevention initiatives. Prev Sci. 2005;6(4):319325. doi:10.1007/s11121-005-0016-z

28. Ribisl KM, Luke DA, Bohannon DL, Sorg AA, MorelandRussell S. Reducing disparities in tobacco retailer density by banning tobacco product sales near schools. Nicotine Tob Res. 2017;19(2):239-244. doi:10.1093/ntr/ntw185

29. Ribisl KM, D’Angelo H, Feld AL, et al. Disparities in tobacco marketing and product availability at the point of sale: Results of a national study. Prev Med. 2017;105:381-388. doi:10.1016/j.ypmed.2017.04.010

30. Mennis J, Mason M, Way T, Zaharakis N. The role of tobacco outlet density in a smoking cessation intervention for urban youth. Health Place. 2016;38:3947. doi:10.1016/j.healthplace.2015.12.008

31. Baumann AW, Kohler C, Kim YI, et al. Differences in electronic cigarette awareness, use history, and advertisement exposure between Black and White hospitalized cigarette smokers. J Cancer Educ. 2015;30(4):648-654. doi:10.1007/s13187-014-0767-y

32. Iglesias-Rios L, Parascandola M. A historical review of R.J. Reynolds' strategies for marketing tobacco to Hispanics in the United States. Am J Public Health. 2013;103(5):e15-e27. doi:10.2105/ajph.2013.301256

33. Acevedo-Garcia D, Barbeau E, Bishop JA, Pan J, Emmons KM. Undoing an epidemiological paradox: the tobacco industry's targeting of US Immigrants. Am J Public Health. 2004;94(12):2188-2193. doi:10.2105/ajph.94.12.2188

34. Wada P, Lam CN, Burner E, Terp S, Menchine M, Arora S. Exposure to and use of electronic cigarettes: does language matter? Ethn Dis. 2017;27(3):217-222. doi:10.18865/ed.27.3.217

35. Fernandez S, Hickman N, Klonoff EA, et al. Cigarette advertising in magazines for Latinas, White women, and men, 1998--2002: a preliminary investigation. J Community Health. 2005;30(2):141-151. doi:10.1007/s10900-004-1097-5

36. Fellows KL, Rubin DL. Identities for sale: How the tobacco industry construed Asians, Asian Americans, and Pacific Islanders. J Intercult Comm Res. 2006;35(3). doi:10.1080/17475750601027089

37. Henriksen L, Andersen-Rodgers E, Zhang X, et al. Neighborhood variation in the price of cheap tobacco products in California: results from Healthy Stores for a Healthy Community. Nicotine Tob Res. 2017;19(11):1330-1337. doi:10.1093/ntr/ntx089

38. D'Silva J, O'Gara E, Villaluz NT. Tobacco industry misappropriation of American Indian culture and traditional tobacco. Tob Control. 2018;27(e1):e57-e64. doi:10.1136/tobaccocontrol-2017-053950

39. Lee JG, Sun DL, Schleicher NM, Ribisl KM, Luke DA, Henriksen L. Inequalities in tobacco outlet density by race, ethnicity and socioeconomic status, 2012, USA: results from the ASPiRE Study. J Epidemiol Community Health. 2017;71(5):487-492. doi:10.1136/jech-2016-208475

40. John R, Cheney MK, Azad MR. Point-of-sale marketing of tobacco products: taking advantage of the socially disadvantaged? J Health Care Poor Underserved. 2009;20(2):489-506. doi:10.1353/hpu.0.0147

41. Toomey TL, Chen V, Forster JL, Van Coevering P, Lenk KM. Do cigarette prices vary by brand, neighborhood, and store characteristics? Public Health Rep. 2009;124(4):535540. doi:10.1177/003335490912400410

42. Siahpush M, Farazi PA, Kim J, et al. Social disparities in exposure to point-of-sale cigarette marketing. Int J Environ Res Public Health. 2016;13(12):1263-1271. doi:10.3390/ijerph13121263

43. Cantrell J, Kreslake JM, Ganz O, et al. Marketing little cigars and cigarillos: advertising, price, and associations with neighborhood demographics. Am J Public Health. 2013;103(10):1902-1909. doi:10.2105/ajph.2013.301362

44. Kostygina G, Glantz SA, Ling PM. Tobacco industry use of flavours to recruit new users of little cigars and cigarillos. Tob Control. 2016;25(1):66-74. doi:10.1136/tobaccocontrol-2014-051830

45. Ganz O, Cantrell J, Moon-Howard J, Aidala A, Kirchner TR, Vallone D. Electronic cigarette advertising at the point-of-sale: a gap in tobacco control research. Tob Control. 2015;24(e1):e110-e112. doi:10.1136/tobaccocontrol-2013-051337

46. Widome R, Brock B, Klein EG, Forster JL. Smokeless tobacco advertising at the point of sale: prevalence, placement, and demographic correlates. Nicotine Tob Res. 2012;14(2):217-223. doi:10.1093/ntr/ntr188

47. Weiss JW, Cen S, Schuster DV, et al. Longitudinal effects of pro-tobacco and anti-tobacco messages on adolescent smoking susceptibility. Nicotine Tob Res. 2006;8(3):455465. doi:10.1080/14622200600670454

48. Yu M, Hahm HC, Vaughn MG. Intrapersonal and interpersonal determinants of smoking status among Asian American adolescents: findings from a national sample. Nicotine Tob Res. 2010;12(8):801-809. doi:10.1093/ntr/ntq100

49. Lee D, Cutler BD, Burns J. The marketing and demarketing of tobacco products to low-income African-Americans. Health Mark Q. 2004;22(2):51-68. doi:10.1300/j026v22n02_04

50. Vogeltanz-Holm N, Holm JE, White Plume J, Poltavski D. Confirmed recall and perceived effectiveness of tobacco countermarketing media in rural youth. Prev Sci. 2009;10(4):325-334. doi:10.1007/s11121-009-0134-0

51. Flynn BS, Worden JK, Bunn JY, et al. Mass media interventions to reduce youth smoking prevalence. 
Am J Prev Med. 2010;39(1):53-62. doi:10.1016/j. amepre.2010.03.008

52. Fosson GH, McCallum DM, Conaway MB. Antismoking mass media campaigns and support for smoke-free environments, Mobile County, Alabama, 2011-2012. Prev Chronic Dis. 2014;11. doi:10.5888/pcd11.140106

53. Cowell AJ, Farrelly MC, Chou R, Vallone DM. Assessing the impact of the national 'truth' antismoking campaign on beliefs, attitudes, and intent to smoke by race/ethnicity. Ethn Health. 2009;14(1):75-91. doi:10.1080/13557850802257715

54. Terry-McElrath YM, Wakefield MA, Emery S, et al. State anti-tobacco advertising and smoking outcomes by gender and race/ethnicity. Ethn Health. 2007;12(4):339362. doi:10.1080/13557850701300723

55. Farrelly MC, Nonnemaker J, Davis KC, Hussin A. The influence of the national truth ${ }^{\circledR}$ campaign on smoking initiation. Am J Prev Med. 2009;36(5):379-384. doi:10.1016/j.amepre.2009.01.019

56. Richardson A, Cullen J, Mowery P, McCausland K, Vallone D. The path to quit: how awareness of a largescale mass-media smoking cessation campaign promotes quit attempts. Nicotine Tob Res. 2011;13(11):10981105. doi:10.1093/ntr/ntr158

57. Vallone DM, Niederdeppe J, Richardson AK, Patwardhan P, Niaura R, Cullen J. A national mass media smoking cessation campaign: effects by race/ethnicity and education. Am J Health Promot. 2011;25(5 Suppl):S38-S50. doi:10.4278/ajhp.100617-quan-201

58. Czarnecki KD, Vichinsky LE, Ellis JA, Perl SB. Media campaign effectiveness in promoting a smoking-cessation program. Am J Prev Med. 2010;38(3 Suppl):S333-S342. doi:10.1016/j.amepre.2009.11.019

59. Kelly KJ, Stanley LR, Comello ML, Gonzalez GR. Tobacco counteradvertisements aimed at bicultural Mexican American youth: the impact of language and theme. J Health Commun. 2006;11(5):455-476. doi:10.1080/10810730600751920

60. Kelly K, Comello MLG, Stanley LR, Gonzalez GR. The power of theme and language in multicultural communities: which tobacco prevention messages are most persuasive to Mexican-American youth? J Advertising Res. 2010;50(3):265-278. doi:10.2501/s0021849910091439

61. Shen L, Monahan JL, Rhodes N, Roskos-Ewoldsen DR. The impact of attitude accessibility and decision style on adolescents' biased processing of health-related public service announcements. Comm Res. 2009;36(1):104128. doi:10.1177/0093650208326466

62. Tharp-Taylor S, Fryer CS, Shadel WG. Targeting antismoking messages: does audience race matter? Addict Behav. 2012;37(7):844-847. doi:10.1016/j.addbeh.2012.03.019

63. Nonnemaker JM, Allen JA, Davis KC, Kamyab K, Duke JC, Farrelly MC. The influence of antismoking television advertisements on cessation by race/ethnicity, socioeconomic status, and mental health status. PLoS One. 2014;9(7):e102943. doi:10.1371/journal.pone.0102943

64. Patterson Silver Wolf DA, Tovar M, Thompson K, et al. Speaking out about physical harms from tobacco use: response to graphic warning labels among American Indian/Alaska Native communities. BMJ Open. 2016;6(3):e008777. doi:10.1136/bmjopen-2015-008777

65. Graham AL, Milner P, Saul JE, Pfaff L. Online advertising as a public health and recruitment tool: comparison of different media campaigns to increase demand for smoking cessation interventions. J Med Internet Res. 2008;10(5):e50. doi:10.2196/jmir.1001

66. Russo ET, Reid M, Taher R, Sharifi M, Shah SN. Referral strategies to a tobacco quitline and racial and/or ethnic differences in participation. Pediatrics. 2018;141(Suppl 1):S30-S39. doi:10.1542/peds.2017-1026g

67. Parvanta S, Gibson L, Forquer H, et al. Applying quantitative approaches to the formative evaluation of antismoking campaign messages. Soc Mar Q. 2013;19(4):242-264. doi:10.1177/1524500413506004

68. Webb MS, Baker EA, Rodriguez de Ybarra D. Effects of culturally specific cessation messages on theoretical antecedents of behavior among low-income African American smokers. Psychol Addict Behav. 2010;24(2):333-341. doi:10.1037/a0018700

69. Pinsker EA, Call KT, Tanaka A, et al. The development of culturally appropriate tobacco prevention videos targeted toward Somali youth. Prog Community Health Partnersh. 2017;11(2):129-136. doi:10.1353/cpr.2017.0017

70. Graham AL, Fang Y, Moreno JL, et al. Online advertising to reach and recruit Latino smokers to an internet cessation program: impact and costs. J Med Internet Res. 2012;14(4):e116. doi:10.2196/jmir.2162

71. Baig SA, Pepper JK, Morgan JC, Brewer NT. Social identity and support for counteracting tobacco company marketing that targets vulnerable populations. Soc Sci Med. 2017;182:136-141. doi:10.1016/j.socscimed.2017.03.052

72. Peters Jr RJ, Kelder SH, Prokhorov A, et al. The relationship between perceived youth exposure to anti-smoking advertisements: how perceptions differ by race. J Drug Educ. 2005;35(1):47-58. doi:10.2190/8063-qp4l-t5a5-b207

73. Barbeau EM, Leavy-Sperounis A, Balbach ED. Smoking, social class, and gender: what can public health learn from the tobacco industry about disparities in smoking? Tob Control. 2004;13(2):115-120. doi:10.1136/tc.2003.006098

74. Scott MM, Cohen DA, Schonlau M, Farley TA, Bluthenthal RN. Alcohol and tobacco marketing: evaluating compliance with outdoor advertising guidelines. Am J Prev Med. 2008;35(3):203-209. doi:10.1016/j.amepre.2008.05.026

75. Barbeau EM, Wolin KY, Naumova EN, Balbach E. Tobacco advertising in communities: associations with race and class. Prev Med. 2005;40(1):16-22. doi:10.1016/j.ypmed.2004.04.056

76. Siahpush M, Jones PR, Singh GK, Timsina LR, Martin J. 
The association of tobacco marketing with median income and racial/ethnic characteristics of neighbourhoods in Omaha, Nebraska. Tob Control. 2010;19(3):256-258. doi:10.1136/tc.2009.032185

77. Cantrell J, Ganz O, Anesetti-Rothermel A, et al. Cigarette price variation around high schools: evidence from Washington DC. Health Place. 2015;31:193-198. doi:10.1016/j.healthplace.2014.12.002

78. Cantrell J, Anesetti-Rothermel A, Pearson JL, Xiao H, Vallone D, Kirchner TR. The impact of the tobacco retail outlet environment on adult cessation and differences by neighborhood poverty. Addiction. 2015;110(1):152-161. doi:10.1111/add.12718

79. Durkin SJ, Biener L, Wakefield MA. Effects of different types of antismoking ads on reducing disparities in smoking cessation among socioeconomic subgroups. Am J Public Health. 2009;99(12):2217-2223. doi:10.2105/ajph.2009.161638

80. Niederdeppe J, Fiore MC, Baker TB, Smith SS. Smokingcessation media campaigns and their effectiveness among socioeconomically advantaged and disadvantaged populations. Am J Public Health. 2008;98(5):916-924. doi:10.2105/ajph.2007.117499

81. Niederdeppe J, Farrelly MC, Nonnemaker J, Davis KC, Wagner L. Socioeconomic variation in recall and perceived effectiveness of campaign advertisements to promote smoking cessation. Soc Sci Med. 2011;72(5):773-780. doi:10.1016/j.socscimed.2010.12.025

82. Macy JT, Chassin L, Presson CC, Sherman JW. Changing implicit attitudes toward smoking: results from a web-based approach-avoidance practice intervention. J Behav Med. 2015;38(1):143-152. doi:10.1007/s10865-014-9585-2

83. McCullough A, Meernik C, Baker H, Jarman K, Walsh B, Goldstein AO. Perceptions of tobacco control media campaigns among smokers with lower socioeconomic status. Health Promot Pract. 2018;19(4):550-559. doi:10.1177/1524839917741485

84. Strickland JR, Smock N, Casey C, Poor T, Kreuter MW, Evanoff BA. Development of targeted messages to promote smoking cessation among construction trade workers. Health Educ Res. 2015;30(1):107-120. doi:10.1093/her/cyu050

85. Vallone DM, Allen JA, Xiao H. Is socioeconomic status associated with awareness of and receptivity to the truth campaign? Drug Alcohol Depend. 2009;104 Suppl 1:S115-S120. doi:10.1016/j.drugalcdep.2009.03.015

86. Brown-Johnson CG, England LJ, Glantz SA, Ling PM. Tobacco industry marketing to low socioeconomic status women in the U.S.A. Tob Control. 2014;23(e2):e139-146. doi:10.1136/tobaccocontrol-2013-051224

87. Hammond D, Doxey J, Daniel S, Bansal-Travers M. Impact of female-oriented cigarette packaging in the United States. Nicotine Tob Res. 2011;13(7):579-588. doi:10.1093/ntr/ntr045

88. Toll BA, Ling PM. The Virginia Slims identity crisis: an inside look at tobacco industry marketing to women. Tob Control. 2005;14(3):172-180. doi:10.1136/tc.2004.008953

89. Carpenter CM, Wayne GF, Connolly GN. Designing cigarettes for women: new findings from the tobacco industry documents. Addiction. 2005;100(6):837-851. doi:10.1111/j.1360-0443.2005.01072.x

90. Pierce JP, Messer K, James LE, et al. Camel No. 9 cigarettemarketing campaign targeted young teenage girls. Pediatrics. 2010;125(4):619-626. doi:10.1542/peds.2009-0607

91. Shadel WG, Niaura R, Abrams DB. Adolescents' responses to the gender valence of cigarette advertising imagery: the role of affect and the selfconcept. Addict Behav. 2004;29(9):1735-1744. doi:10.1016/j.addbeh.2004.03.042

92. Dirocco DN, Shadel WG. Gender differences in adolescents' responses to themes of relaxation in cigarette advertising: Relationship to intentions to smoke. Addict Behav. 2007;32(2):205-213. doi:10.1016/j.addbeh.2006.03.035

93. Scales MB, Monahan JL, Rhodes N, Roskos-Ewoldsen D, Johnson-Turbes A. Adolescents' perceptions of smoking and stress reduction. Health Educ Behav. 2009;36(4):746-758. doi:10.1177/1090198108317628

94. Carson NJ, Rodriguez D, Audrain-McGovern J. Investigation of mechanisms linking media exposure to smoking in high school students. Prev Med. 2005;41(2):511-520. doi:10.1016/j.ypmed.2005.01.002

95. Mejia AB, Ling PM. Tobacco industry consumer research on smokeless tobacco users and product development. Am J Public Health. 2010;100(1):78-87. doi:10.2105/ajph.2008.152603

96. Romito L, Saxton MK. Impact of promotions on awareness, trial, and likelihood of trial of new dissolvable tobacco. Am J Health Promot. 2014;28(4):251-258. doi:10.4278/ajhp.120926-quan-469

97. Kennedy MG, Genderson MW, Sepulveda AL, et al. Increasing tobacco quitline calls from pregnant African American women: the 'one tiny reason to quit' social marketing campaign. J Womens Health. 2013;22(5):432438. doi:10.1089/jwh.2012.3845

98. Samu S, Bhatnagar N. The efficacy of anti-smoking advertisements: the role of source, message, and individual characteristics. Int J Nonprofit Volunt Sect Mark. 2008;13(3):237-250. doi:10.1002/nvsm.326

99. Shen L. Targeting smokers with empathy appeal antismoking public service announcements: a field experiment. J Health Commun. 2015;20(5):573-580. doi:10.1080/10810730.2015.1012236

100.Smith KH, Stutts MA. The influence of individual factors on the effectiveness of message content in antismoking advertisements aimed at adolescents. J Consumer Affairs. 2006;40:261-293. doi:10.1111/j.1745-6606.2006.00058.x

101.Yom-Tov E, Muennig P, El-Sayed AM. Web-based antismoking advertising to promote smoking cessation: a randomized controlled trial. J Med Internet Res. 
2016;18(11):e306. doi:10.2196/jmir.6563

102.Lavery AM, Nair U, Bass SB, Collins BN. The influence of health messaging source and frequency on maternal smoking and child exposure among low-income mothers. J Commun Health. 2016;9(3):200-209. doi:10.1080/17538068.2016.1231858

103.Bernat DH, Choi K. Differences in cigarette use and the tobacco environment among youth living in metropolitan and nonmetropolitan areas. J Rural Health. 2018;34(1):80-87. doi:10.1111/jrh.12194

104.Pesko MF, Robarts AMT. Adolescent tobacco use in urban versus rural areas of the United States: the influence of tobacco control policy environments. J Adolesc Health. 2017;61(1):70-76. doi:10.1016/j.jadohealth.2017.01.019

105.Couch ET, Darius EF, Walsh MM, Chaffee BW. ST product characteristics and relationships with perceptions and behaviors among rural adolescent males: a qualitative study. Health Educ Res. 2017;32(6):537545. doi:10.1093/her/cyx067

106.Nemeth JM, Liu ST, Klein EG, Ferketich AK, Kwan MP, Wewers ME. Factors influencing smokeless tobacco use in rural Ohio Appalachia. J Community Health. 2012;37(6):1208-1217. doi:10.1007/s10900-012-9556-x

107.Klein EG, Ferketich AK, Abdel-Rasoul M, Kwan MP, Kenda L, Wewers ME. Smokeless tobacco marketing and sales practices in Appalachian Ohio following federal regulations. Nicotine Tob Res. 2012;14(7):880-884. doi:10.1093/ntr/ntr243

108.Zollinger TW, Saywell Jr RM, Overgaard AD, Przybylski MJ, Dutta-Bergman M. Antitobacco media awareness of rural youth compared to suburban and urban youth in Indiana. J Rural Health. 2006;22(2):119-123. doi:10.1111/j.1748-0361.2006.00019.x

109.Duke JC, Vallone DM, Allen JA, et al. Increasing youths' exposure to a tobacco prevention media campaign in rural and low-population-density communities. Am J Public Health. 2009;99(12):2210-2216. doi:10.2105/ajph.2008.155127

110.Brewer HJ, Kulik KS, Klingaman L, Deutschlander S, Black C. Teenagers' use of tobacco and their perceptions of tobacco control initiatives. J Drug Educ. 2012;42(3):255-266. doi:10.2190/de.42.3.a

111.Riker CA, Butler KM, Ricks JM, et al. Creating effective media messaging for rural smoke-free policy. Public Health Nurs. 2015;32(6):613-624. doi:10.1111/phn.12188

112.Kostygina G, Hahn EJ, Rayens MK. 'It's about the smoke, not the smoker': messages that motivate rural communities to support smoke-free policies. Health Educ Res. 2014;29(1):58-71. doi:10.1093/her/cyt087

113.Haddock CK, Parker LC, Taylor JE, Poston WS, Lando H, Talcott GW. An analysis of messages about tobacco in military installation newspapers. Am J Public Health. 2005;95(8):1458-1463. doi:10.2105/ajph.2004.048454

114.Haddock CK, Jahnke SA, Poston WS, Williams LN.
Cigarette prices in military retail: a review and proposal for advancing military health policy. Mil Med. 2013;178(5):563-569. doi:10.7205/milmed-d-12-00517

115.Smith EA, Malone RE. Tobacco promotion to military personnel: 'the plums are here to be plucked'. Mil Med. 2009;174(8):797-806. doi:10.7205/milmed-d-04-4108

116.Joseph AM, Muggli M, Pearson KC, Lando H. The cigarette manufacturers' efforts to promote tobacco to the U.S. military. Mil Med. 2005;170(10):874-880. doi:10.7205/milmed.170.10.874

117.Smith EA, Malone RE. 'Everywhere the soldier will be': wartime tobacco promotion in the US military. Am J Public Health. 2009;99(9):1595-1602. doi:10.2105/ajph.2008.152983

118.Hoffman KM, Haddock CK, Poston WS, Taylor JE, Lando HA, Shelton S. A formative examination of messages that discourage tobacco use among junior enlisted members of the United States military. Nicotine Tob Res. 2008;10(4):653-661. doi:10.1080/14622200801978730

119.Haddock CK, Hoffman K, Taylor JE, Schwab L, Poston WS, Lando HA. An analysis of messages about tobacco in the Military Times magazines. Nicotine Tob Res. 2008;10(7):1191-1197. doi:10.1080/14622200802163126

120.Smith EA, Malone RE. Mediatory myths in the U.S. military: tobacco use as 'stress relief'. Am J Health Promot. 2014;29(2):115-122. doi:10.4278/ajhp.121009-qual-491

121.Lando HA, Michaud ME, Poston WS, Jahnke SA, Williams L, Haddock CK. Banning cigarette smoking on US Navy submarines: a case study. Tob Control. 2015;24(e3):e188-e192. doi:10.1136/tobaccocontrol-2014-051624

122.Popova L, Linde BD, Bursac Z, et al. Testing antismoking messages for Air Force trainees. Tob Control. 2016;25(6):656663. doi:10.1136/tobaccocontrol-2015-052477

123.Stevens P, Carlson LM, Hinman JM. An analysis of tobacco industry marketing to lesbian, gay, bisexual, and transgender (LGBT) populations: strategies for mainstream tobacco control and prevention. Health Promot Pract. 2004;5(3 Suppl):129S-134S. doi:10.1177/1524839904264617

124.Smith EA, Offen N, Malone RE. What makes an ad a cigarette ad? Commercial tobacco imagery in the lesbian, gay, and bisexual press. J Epidemiol Community Health. 2005;59(12):1086-1091. doi:10.1136/jech.2005.038760

125.Dilley JA, Spigner C, Boysun MJ, Dent CW, Pizacani BA. Does tobacco industry marketing excessively impact lesbian, gay and bisexual communities? Tob Control. 2008;17(6):385-390. doi:10.1136/tc.2007.024216

126.Smith EA, Thomson K, Offen N, Malone RE. 'If you know you exist, it's just marketing poison': meanings of tobacco industry targeting in the lesbian, gay, bisexual, and transgender community. Am J Public Health. 2008;98(6):996-1003. doi:10.2105/ajph.2007.118174

127. Fallin A, Lee YO, Bennett K, Goodin A. Smoking cessation awareness and utilization among Lesbian, Gay, Bisexual, and Transgender adults: an analysis of the 2009-2010 
National Adult Tobacco Survey. Nicotine Tob Res. 2016;18(4):496-500. doi:10.1093/ntr/ntv103

128.Plant A, Montoya JA, Tyree R, et al. The break up: evaluation of an anti-smoking educational campaign for Lesbians, Gays, and Bisexuals in Los Angeles County. J Health Commun. 2017;22(1):29-36. doi:10.1080/10810730.2016.1247485

129.Apollonio DE, Malone RE. Marketing to the marginalised: tobacco industry targeting of the homeless and mentally ill. Tob Control. 2005;14(6):409-415. doi:10.1136/tc.2005.011890

130.Campbell BK, Le T, Andrews KB, Pramod S, Guydish J. Smoking among patients in substance use disorders treatment: associations with tobacco advertising, anti-tobacco messages, and perceived health risks. Am J Drug Alcohol Abuse. 2016;42(6):649-656. doi:10.1080/00952990.2016.1183021

131. Young-Wolff KC, Henriksen L, Delucchi K, Prochaska JJ. Tobacco retailer proximity and density and nicotine dependence among smokers with serious mental illness. Am J Public Health. 2014;104(8):1454-1463. doi:10.2105/ajph.2014.301917

132. Coletti DJ, Brunette M, John M, Kane JM, Malhotra AK, Robinson DG. Responses to tobacco smoking-related health messages in young people with recent-onset schizophrenia. Schizophr Bull. 2015;41(6):1256-1265. doi:10.1093/schbul/sbv122

133.Lempert LK, Glantz SA. Tobacco industry promotional strategies targeting American Indians/Alaska Natives and exploiting tribal sovereignty. Nicotine Tob Res. 2019;21(7):940-948. doi:10.1093/ntr/nty048

134.Levy DT, Chaloupka F, Gitchell J. The effects of tobacco control policies on smoking rates: a tobacco control scorecard. J Public Health Manag Pract. 2004;10(4):338353. doi:10.1097/00124784-200407000-00011

135.Ackerman A, Etow A, Bartel S, Ribisl KM. Reducing the density and number of tobacco retailers: policy solutions and legal issues. Nicotine Tob Res. 2016;19(2):133-140. doi: $10.1093 / \mathrm{ntr} / \mathrm{ntw} 124$

136. West JH, Romero RA, Trinidad DR. Adolescent receptivity to tobacco marketing by racial/ethnic groups in California. Am J Prev Med. 2007;33(2):121-123. doi:10.1016/j.amepre.2007.03.014

137.Hrywna M, Delnevo CD, Lewis MJ. Adult recall of tobacco advertising on the Internet. Nicotine Tob Res. 2007;9(11):1103-1107. doi:10.1080/14622200701488442

138.Ruel E, Mani N, Sandoval A, et al. After the Master Settlement Agreement: Trends in the American Tobacco Retail Environment from 1999 to 2002. Health Promot Pract. 2004;5(3 Suppl):99S-110S. doi:10.1177/1524839904264603

139.Soneji S, Ambrose BK, Lee W, Sargent J, Tanski S. Direct-to-consumer tobacco marketing and its association with tobacco use among adolescents and young adults. J Adolesc Health. 2014;55(2):209-215. doi:10.1016/j.jadohealth.2014.01.019

140.Anderson SJ, Glantz SA, Ling PM. Emotions for sale: cigarette advertising and women's psychosocial needs. Tob Control. 2005;14(2):127-135. doi:10.1136/tc.2004.009076

141. Wilkinson AV, Vandewater EA, Carey FR, Spitz MR. Exposure to pro-tobacco messages and smoking status among Mexican origin youth. J Immigr Minor Health. 2014;16(3):385-393. doi:10.1007/s10903-013-9827-3

142.Henriksen L, Feighery EC, Schleicher NC, Cowling DW, Kline RS, Fortmann SP. Is adolescent smoking related to the density and proximity of tobacco outlets and retail cigarette advertising near schools? Prev Med. 2008;47(2):210-214. doi:10.1016/j.ypmed.2008.04.008

143.Siahpush M, Tibbits M, Soliman GA, et al. Neighbourhood exposure to point-of-sale price promotions for cigarettes is associated with financial stress among smokers: results from a populationbased study. Tob Control. 2017;26(6):703-708. doi:10.1136/tobaccocontrol-2016-053339

144.Dewhirst T, Lee WB, Fong GT, Ling PM. Exporting an inherently harmful product: the marketing of virginia slims cigarettes in the United States, Japan, and Korea. J Bus Ethics. 2016;139(1):161-181. doi:10.1007/s10551-015-2648-7

145.Basch CH, Mongiovi J, Hillyer GC, Ethan D, Hammond R. An analysis of electronic cigarette and cigarette advertising in US women's magazines. Int J Prev Med. 2016;7:103. doi:10.4103/2008-7802.190089

146.Hillier A, Chilton M, Zhao QW, Szymkowiak D, Coffman R, Mallya G. Concentration of tobacco advertisements at SNAP and WIC stores, Philadelphia, Pennsylvania, 2012. Prev Chronic Dis. 2015;12:E15. doi:10.5888/pcd12.140133

147.Robinson CD, Pickworth WB, Heishman SJ, et al. Black cigarette smokers report more attention to smoking cues than White smokers: implications for smoking cessation. Nicotine Tob Res. 2015;17(8):1022-1028. doi: $10.1093 / \mathrm{ntr} / \mathrm{ntu} 263$

148.Fallin A, Neilands TB, Jordan JW, Hong JS, Ling PM. Wreaking 'havoc' on smoking: Social branding to reach young adult 'partiers' in Oklahoma. Am J Prev Med. 2015;48(1) Suppl 1:S78-S85. doi:10.1016/j.amepre.2014.09.008

149.Peebles K, Hall MG, Pepper JK, Byron MJ, Noar SM, Brewer NT. Adolescents' responses to pictorial warnings on their parents' cigarette packs. J Adolesc Health. 2016;59(6):635641. doi:10.1016/j.jadohealth.2016.07.003

150.Lee JG, Baker HM, Ranney LM, Goldstein AO. Neighborhood inequalities in retailers' compliance with the Family Smoking Prevention and Tobacco Control Act of 2009, January 2014-July 2014. Prev Chronic Dis. 2015;12:E171. doi:10.5888/pcd12.150231

151.Johnson DM, Wine LA, Zack S, et al. Designing a tobacco counter-marketing campaign for African American youth. Tob Induc Dis. 2008;4(August). doi:10.1186/1617-9625-4-7 152.Haviland L, Thornton AH, Carothers S, et al. 
Giving infants a great start: launching a national smoking cessation program for pregnant women. Nicotine Tob Res. 2004;6(Suppl 2):S181-S188. doi:10.1080/14622200410001669114

153.England L, Tong VT, Rockhill K, et al. Evaluation of a federally funded mass media campaign and smoking cessation in pregnant women: a population-based study in three states. BMJ Open. 2017;7(12):e016826. doi:10.1136/bmjopen-2017-016826

154.Parks MJ, Kim S. Interpersonal Communication in Response to an Intervention and Its Impact on Smoking Cessation Within a Low-Income Population. Health Educ Behav. 2018;45(4):550-558. doi:10.1177/1090198117749258

155.Kim J, Cao X, Meczkowski E. Does stigmatization motivate people to quit smoking? Examining the effect of stigmatizing anti-smoking campaigns on cessation intention. Health Commun. 2018;33(6):681-689. doi:10.1080/10410236.2017.1299275

156.Rudov L, McCormick-Ricket I, Kingsmill D, Ledford C, Carton T. Evaluation recommendations for nonprofit social marketing campaigns: An example from the Louisiana Campaign for Tobacco-Free Living. International Journal of Nonprofit and Voluntary Sector Marketing. 2017;22(1):e1570. doi:10.1002/nvsm.1570

157.Khaddouma A, Gordon KC, Fish LJ, Bilheimer A, Gonzalez A, Pollak KI. Relationships among spousal communication, self-efficacy, and motivation among expectant Latino fathers who smoke. Health Psychol. 2015;34(10):1038-1042. doi:10.1037/hea0000224

158.Menzie NS, Simmons VN, Quinn GP, et al. Acceptability and cultural appropriateness of self-help booklets for relapse prevention in Puerto Rico. J Cancer Educ. 2015;30(3):585-592. doi:10.1007/s13187-014-0729-4

159.Richardson A, Ganz O, Vallone D. The cigar ambassador: how Snoop Dogg uses Instagram to promote tobacco use. Tob Control. 2014;23(1):79-80. doi:10.1136/tobaccocontrol-2013-051037

160.Kostygina G, Tran H, Shi Y, Kim Y, Emery S. 'Sweeter Than a Swisher': amount and themes of little cigar and cigarillo content on Twitter. Tob Control. 2016;25(Suppl 1):i75-i82. doi:10.1136/tobaccocontrol-2016-053094

161. Timberlake DS, Nikitin D, Garcia-Cano J, Cino S, Savkina M, Pechmann C. Linking the content to demographic reach of online advertising of electronic nicotine delivery systems. Tob Control. 2018;27(4):463-469. doi:10.1136/tobaccocontrol-2016-053473

162.Ashford K, Rayens E, Wiggins AT, Rayens MK, Fallin A, Sayre MM. Advertising exposure and use of e-cigarettes among female current and former tobacco users of childbearing age. Public Health Nurs. 2017;34(5):430436. doi:10.1111/phn.12334

163.Garcia R, Sidhu A, Allem JP, Baezconde-Garbanati L, Unger JB, Sussman S. Marketing activities of vape shops across racial/ethnic communities. Tob Prev Cessation.
2016;2(Supplement). doi:10.18332/tpc/76398

164.Kates FR. Spatial analysis and correlates of waterpipe tobacco smoking among college students in the United States. University of South Carolina; 2015. https:// scholarcommons.sc.edu/etd/3067. Accessed April 1, 2018.

165. Tat J, Nguy M, Tong EK, Cheng AJ, Chung LY, Sadler GR. Disseminating tobacco control information to Asians and Pacific Islanders. J Cancer Educ. 2015;30(1):26-30. doi:10.1007/s13187-014-0695-x

166.D'Angelo H, Ammerman A, Gordon-Larsen P, Linnan L, Lytle L, Ribisl KM. Sociodemographic Disparities in Proximity of Schools to Tobacco Outlets and Fast-Food Restaurants. Am J Public Health. 2016;106(9):15561562. doi:10.2105/ajph.2016.303259

167. Sussman S, Garcia R, Cruz TB, Baezconde-Garbanati L, Pentz MA, Unger JB. Consumers' perceptions of vape shops in Southern California: an analysis of online Yelp reviews. Tob Induc Dis. 2014;12(November). doi:10.1186/s12971-014-0022-7

\section{CONFLICTS OF INTEREST}

The authors have completed and submitted the ICMJE Form for Disclosure of Potential Conflicts of Interest and none was reported.

\section{FUNDING}

This study was completed as part of the collaborative research being conducted by the National Institutes of Health $(\mathrm{NIH})$ and Food and Drug Administration (FDA) Tobacco Centers of Regulatory Science (TCORS) Vulnerable Populations Workgroup. The review reported in this publication was supported by grant numbers P50CA180905 and U54CA180905 from the National Cancer Institute $(\mathrm{NCl})$ and the FDA Center for Tobacco Products (CTP) for Cruz, Unger, Lienemann, Baezconde-Garbanati and Soto; grant number T32CA009492-29 from $\mathrm{NCl}$ for Lienemann; grant number U54CA189222 under a subcontract to Westat from NCI, FDA and the Center for Evaluation and Coordination of Training and Research (CECTR) in Tobacco Regulatory Science for Rose; grant number P50 CA180907 from the NCl and FDA CTP for Byron and Huang and the National Research Service Award T32 DA007097 from the National Institute on Drug Abuse for Carroll. The content is solely the responsibility of the authors and does not necessarily represent the official views of the National Institutes of Health or the FDA.

\section{PROVENANCE AND PEER REVIEW}

Not commissioned; externally peer reviewed 